\title{
Construction of Engineering Education Professional Certification System
}

\author{
Yang Zhao \\ Department of Mechanical and Electrical Engineering, Guangdong University of Science \& Technology, \\ Dongguan, China
}

Keywords: engineering education; professional certification; core concept; traditional teaching

\begin{abstract}
The traditional engineering education pays too much attention to the scientific knowledge education based on subject knowledge in the course of course teaching, neglects the training of the ability of engineering practice and innovation, and leads to the serious separation of the students' knowledge and ability, and it is difficult to adapt to the demands of the creative talents of the engineering practice. The achievement-oriented engineering education is goal-oriented, which follows the principle of reverse design, determines the training target by the demand, then decides the graduation requirement by the training goal, and the course system and the course teaching by the requirements of the graduation. Based on the engineering education model of OBE, the teaching reform of the course is carried out. The training target of the course and the teaching content of the integrated design are determined by combining the standard of engineering education professional certification and the CDIO ability outline.
\end{abstract}

\section{Introduction}

After the twenty-first Century, with the deepening of the reform of higher engineering education, practice is the fundamental of engineering major, which has become a common understanding of the international higher engineering education [1]. The higher engineering education circles have studied and discussed how to cultivate the students' engineering practice ability, such as introducing the vocational qualification certificate into the applied undergraduate education, which has achieved good results.

In June 19, 2013, China became a member of the agreement on the mutual recognition of the international undergraduate degree in engineering, and China became the official member of the Washington Agreement in June 2, 2016 [2]. This marked the entry of the engineering education system into the International Engineering Education Alliance [3]. The professional certification of engineering education is an opportunity for the higher engineering education community in China [4] The engineering education community generally believes that the conclusion of the Washington Agreement is beneficial to improve the quality of Engineering Education in China, to promote our country to train engineers in accordance with international standards and to improve the quality of the training of engineers and technicians. It is the basis and key to promote the international mutual recognition of the qualification of our engineers. The accession to the Washington Agreement on higher engineering education indicates that the training of engineering talents in Chinese colleges and universities has entered the substantive stage of internationalization [5]. It has put forward new standards for the training of mechanical and electrical engineering talents in Colleges and universities.

Therefore, the education of mechanical and electrical engineering in Colleges and universities must speed up the pace of internationalization, take a new perspective of talent training, vigorously carry out teaching reform, do a good job in quality control of undergraduate teaching, and meet professional certification. 


\section{The Core Concepts of Engineering Education Professional Certification}

The three core concepts of engineering education professional certification is outcome based education (OBE), student centered and continuous improvement, which are contrasted with the traditional education of content driven and devoted to input. These ideas represent the direction of the reform of engineering education and an innovation of the educational paradigm. OBE is a "result oriented education" or "education based on output". It has achieved good results in guiding teaching design, curriculum system, learning goals, and the construction of teachers. The concept of OBE is from the traditional "Teacher centered" to "student centered", focusing on the expected learning effect, and formulating teaching plans and training programs in accordance with the requirements that students should meet at graduation in order to anticipate the realization of the learning results. It begins with the design of the reverse teaching process from the result, breaks the concrete ideas of the traditional education design, and forms a clear vein of the teaching reform in the new period.

\section{Problems in Traditional Teaching}

\subsection{The unclear purpose of teaching}

Influenced by the traditional scientism education, we pay too much attention to the scientific knowledge education based on subject knowledge in the course setting and teaching process. The ability of engineering practice is ignored, and the cultivation of application and innovation ability directly leads to the serious separation of students' knowledge and ability. In the talent training program, each course does not refine the corresponding teaching objectives according to the professional training goal, and the knowledge, ability and quality of the students are not clear, and the teachers and students are not clear about the teaching purpose of the curriculum. It is not clear why students want to set up this course, what is the role of the course, what needs to be achieved, what is the relationship between the course and the follow-up course, which leads to the students studying for the exam.

\subsection{The unchangeable teaching content and the separated theory from practice}

With the promotion of a new round of educational reform, the curriculum and teaching contents of various engineering specialties have been adjusted accordingly. While the teaching time has been reduced, the requirements of teaching have been improved, and the contradictions of more content and less hours have been intensified. The content of detailed explanation can not be fully expanded, which affects the quality of teaching and increases the difficulty of students' learning.

Most students lack basic engineering background knowledge. Students feel too abstract, difficult to understand, and difficult to understand in the process of learning. The basic concepts and principles of the students are mostly isolated, books, and understanding of knowledge. The theory and engineering practice are often disjointed and lack of model and original. The organic connection between methods and other aspects. The teaching content has a certain degree of difficulty, students can easily generate fear of hardship, affecting the enthusiasm of the students.

\subsection{The single teaching method}

Influenced by traditional educational concepts, the teacher centered teaching mode is still adopted in classroom teaching, and teachers dominate the learning process of students. It is difficult to meet the students' learning requirements by using the teaching method based on "speaking mainly". It is not good to arouse the enthusiasm and initiative of students' study, and is not conducive to the cultivation of students' ability. The traditional spoon feeding teaching method can not only guide students to innovate, but also lead to the loss of students' interest in learning. As the knowledge of the curriculum is more and more difficult and the time of learning is few, many teachers use multimedia teaching methods at present. At the same time, the multimedia teaching method inject new vitality into the teaching form, while there are some negative effects. For example, the speed of teaching is 
quickened, the students are not reacting and the teachers are not explained carefully, especially to the examples. Processing, often in the multimedia courseware on the lead, to consider the problem of thinking and handling skills and techniques, not much, students seem to understand, in fact not mastered.

\subsection{The way of curriculum assessment cannot reflect students' comprehensive ability}

Traditional courses have been adopted in general courses. The final exam results are $60 \%$, and $40 \%$ of normal grades. Taking the examination as the evaluation method, the teacher pays attention to the content and the result of the examination, emphasizes the training of the technical problem solving, neglects the cultivation of the ability of the students' technical application, neglects the training of the students' ability to solve the technical problems in the actual project. The students also deal with the examination for the purpose of learning, and only seek the pass of the examination. Some students only have to deal with the examination before the examination, and the traditional way of examination is easy to cause the students to pay too much attention to the result of the examination and the accumulation of knowledge. At ordinary times, attendance, homework and experiment are the main results. In order to get the normal results, the students who have a bad attitude are often unable to get to their heart, and most of them copy their homework. At present, the general failure rate of courses is relatively high. Every year, graduates fail to graduate normally because of failing the course, which seriously affects the employment of students.

\section{A New Model of Education}

OBE is a new education model based on the results of learning. In concept, it is a "student based" education philosophy, which pays attention to what ability and what can be achieved when students learn some major. It requires that both syllabus, teaching plan and teaching content should be carried out around the achievement of expected learning outcomes. OBE teaching can make the students really master the related knowledge and skills of the majors after the completion of the study, so that the teaching aims can be truly realized and the efficiency of the course teaching can be effectively improved by making clear the training objectives, building up the training system, determining the teaching activities and implementing various teaching evaluation strategies. Compared with the traditional education mode, the biggest difference between OBE education mode and the traditional education mode is to emphasize the cultivation of ability.

OBE mode is mainly applied in engineering education in China. Promoting the reform of engineering education with OBE concept and improving the quality of engineering personnel training has become the focus of attention of local engineering colleges and universities. On the basis of CDIO engineering practice education, Shantou University has actively carried out the reform of OBE education in combination with the international engineering education reform and the OBE development trend of engineering education certification, and has carried out the OBE teaching reform in the professional courses of the Institute of engineering. However, the training and teaching reform under the OBE model have not been widely popularized, and the characteristics and positioning of each school are different, the training objectives are different, the implementation methods are not the same, and OBE based mechanical research papers have not been published.

\section{Implementation Plan}

The curriculum reform project plan is completed in four stages, plan, implement, check and perfect. The specific progress is as shown in Figure 1.

Taking the training of engineering ability as the general goal, making the requirements for the ability to achieve the curriculum, revising the syllabus, making clear the requirements for the training of the relevant teaching knowledge points to the relevant abilities and the ability of the students to achieve, and forming the corresponding student assessment documents and carrying out the implementation in the teaching, the planning phase of the project is finished. 


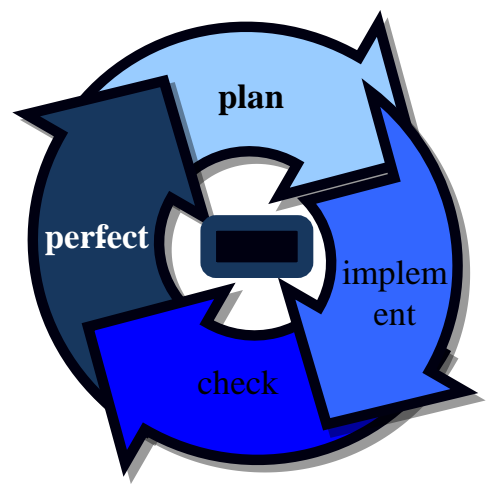

Figure 1. The plan for the implementation of the project

The object of reform and implement new teaching mode and teaching method in the course teaching should be selected, so as to promote the teaching reform. An assessment method focusing on ability training and implement is developed in the course. Some knowledge micro video recording is completed. The implementation phase of the project is finished.

After the end of the stage teaching, the information feedback system is gradually perfected, and a timely summary and self-examination are made to find the place to be improved. The inspection phase of the project is finished.

The teaching experience of the second and third stages is summarized, the recording of micro video is completed, the teaching method is adjusted, the teaching content is optimized, and the evaluation method is modified. The specific indexes in the standard of expectation can reflect the students' engineering ability and engineering quality in the course of the course study. The perfect phase of the project is finished.

\section{Summary}

To grasp the development trend of higher engineering education professional certification, based on the OBE engineering education model, it is imperative to explore and practice the new teaching reform in view of the characteristics of the electronic technology course and the training goal of the students, and to adopt new teaching methods and evaluate the teaching reasonably.

\section{Acknowledgement}

This work was financially supported by the Project of Higher Education Reform in Guangdong University of Science \& Technology.

\section{References}

[1] Y Yang, ZD Chen. Research on Brand Professional Construction Based on Engineering Education Certification. Education Teaching Forum, Vol.12 (2016), p. 58.

[2] XB Liu, LI Xin. Construction of Integrative Case Teaching System of Mechanical Engineering Specialty under Engineering Certification Education. Value Engineering, Vol.34 (2018), p. 99.

[3] J Zhang, YH Chu. Research on the Construction of Mixed Curriculum of Software Engineering Specialty Based on Engineering Education Certification. Modern Computer, Vol.21 (2017), p. 65.

[4] JM Lou, SD Bao. Construction of Engineering Training Center for Engineering Education Professional Certification. Research \& Exploration in Laboratory, Vol.9 (2013), p. 87.

[5] XD Meng, YX Zhou. Construction of Graduation Requirements for Microelectronics Science and Engineering Based on Engineering Education Certification. Education Teaching Forum, Vol.42 (2018), p. 132. 